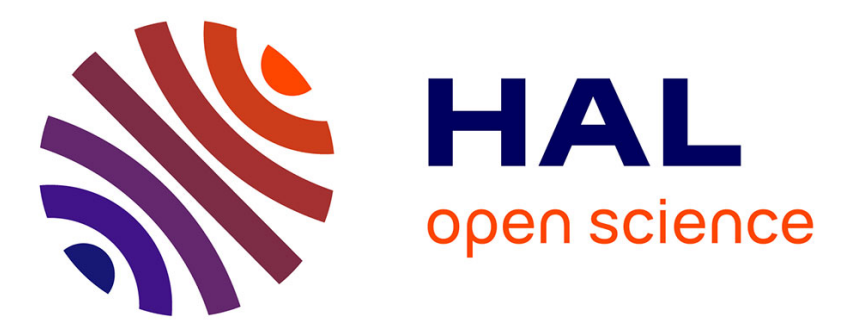

\title{
Model Predictive Tracking Control for a Head-Positioning in a Hard-Disk-Drive
}

Manel Taktak-Meziou, Ahmed Chemori, Jawhar Ghommam, Nabil Derbel

\section{To cite this version:}

Manel Taktak-Meziou, Ahmed Chemori, Jawhar Ghommam, Nabil Derbel. Model Predictive Tracking Control for a Head-Positioning in a Hard-Disk-Drive. MED: Mediterranean Conference on Control and Automation, Jun 2013, Platanias-Chania, Crete, Greece. pp.1368-1373, 10.1109/MED.2013.6608898 . lirmm-00847646

\section{HAL Id: lirmm-00847646 https://hal-lirmm.ccsd.cnrs.fr/lirmm-00847646}

Submitted on 24 Jul 2013

HAL is a multi-disciplinary open access archive for the deposit and dissemination of scientific research documents, whether they are published or not. The documents may come from teaching and research institutions in France or abroad, or from public or private research centers.
L'archive ouverte pluridisciplinaire HAL, est destinée au dépôt et à la diffusion de documents scientifiques de niveau recherche, publiés ou non, émanant des établissements d'enseignement et de recherche français ou étrangers, des laboratoires publics ou privés. 


\title{
Model Predictive Tracking Control for a Head-Positioning in a Hard-Disk-Drive
}

\author{
M. Taktak-Meziou, A. Chemori, J. Ghommam , and N. Derbel
}

\begin{abstract}
This paper deals with the track-following problem of a Read/Write (R/W) head of a Hard-Disk-Drive (HDD) servo-system, which is resolved with two control algorithms generated from Model Predictive Control (MPC). The first approach consists of a classical linear MPC without constraints. The second method is inspired from the MPC technique but uses a reference trajectory to steer the actuator as close as possible to the set-point trajectory. Numerical simulation results of these proposed controllers are presented and compared with those of a classical Proportional Derivative Controller (PID) controller. Different simulation scenarios are presented including nominal case, external disturbance rejection, and robustness under parameters uncertainties.
\end{abstract}

\section{INTRODUCTION}

Hard-Disc-Drive servo systems have recently gained an increasing interest from different research communities. It is well known that these devises are used to store as much data as possible. Therefore, much efforts have been dedicated to improve, not only the shape of such mechanism, but also control techniques to $\mathrm{R} / \mathrm{W}$ information precisely and at fast speed. Fig.1 illustrates the main components of a Hard-Disk-Drive. It consists mainly of a Voice-Coil-Motor (VCM) actuator, several magnetic R/W heads, several disks and a spindle motor. The two principal functions of the

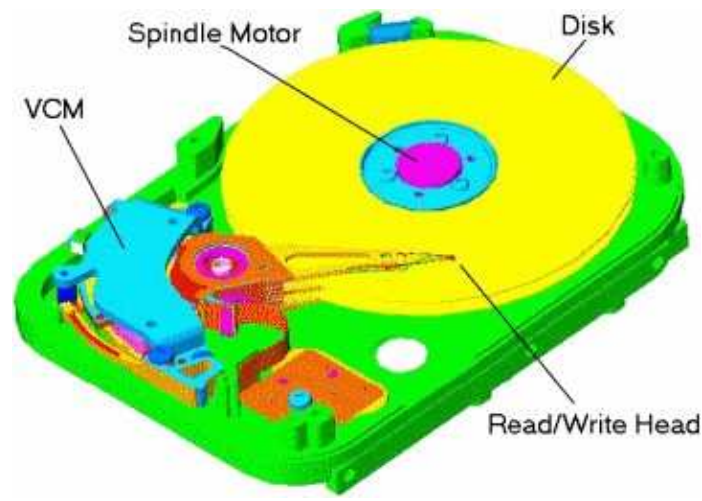

Fig. 1: View of a typical hard-disk-drive

R/W head in a HDD servo-system are seeking control and following control. In seeking control, the head is moved from its present track to a desired destination track in a minimum

M. Taktak-Meziou, J. Ghommam, and N. derbel are with the CEM Lab, Departement of Electrical Engineering, National School of Engineers of Sfax (ENIS), BP, W 3038 Sfax Tunisia. (e-mail: manel.taktak@yahoo.com, jawhar.ghommam@gmail.com,n.derbel@enis.rnu.tn)

A. Chemori is with the LIRMM, University Montpellier 2 / CNRS, UMR5506, CC477, 161 rue Ada, 34095 Montpellier Cedex 5, France (email: Ahmed.Chemori@lirmm.fr) amount of time. Whereas, in following control, the head is maintained as close as possible to the specified track.

From a control point of view, many schemes have already been proposed in the literature for such system. Classical control techniques, such as PID controllers, lead-lag compensators, and different applications of filters [1][2][3] can no longer satisfy the increasing demand for higher performance, such as accuracy, speed and robustness. Many advanced control schemes have been proposed, such as adaptive control [4][5], sliding mode control [6][7][8], robust control [9][10][11] and prediction based state feedback control [29]. Some methods were experimentally tested on a HDD servo system to show their effectiveness on a real system [12][13]. In this work, we propose two linear MPC schemes for a track-following control problem. To the best of the authors' knowledge, such methods were never conducted before on HDD servo-systems.

Thanks to its intrinsic properties and ease of implementation, the MPC is among the most advanced control techniques used in industry today. The main advantage of MPC control is its ability to predict the behavior of the system many samples ahead. Another advantage of this technique is its ability to naturally deal with constraints that are often encountered in real life practice and which are often not well addressed by other control techniques. An overview of this approach is given in [23].

Many applications of such control technique already exist, especially for systems for which the path to follow is well known a priori, such as robots [14] or robotic arms [15], machine tools [16], oil industry [17][18], chemical or biochemical systems [19][20], aerospace [21], thermal [14] and cement industry [15]. It is also a simple way to approach a control law in the time domain [14], and demonstrate, through its qualities, many problems related to the regulation of multivariable systems [30], unstable systems [31], systems with delay [22], nonlinear systems [33], and hybrid systems [32].

In this paper, predictive schemes are applied under nominal conditions as well as in different situations including disturbances and uncertainties on the system parameters. Simulation results are compared with those obtained with a linear PID controller to prove the effectiveness of the proposed solutions.

The outline of this paper is as follow: Section II presents the problem statement. Section III describes the different proposed control solutions. Section IV presents and discusses the simulation results. Concluding remarks are addressed at the end of the paper. 


\section{PROBLEM FORMULATION}

At high frequencies, a HDD is modeled by a linear second order model displaying some resonant modes. These resonant modes result essentially from the system vibration, the pivot bearing, and the quasi rigid body mode. A detailed study on this subject is conducted in [24]. The VCM actuator transfer function can be expressed as follows:

$$
G(s)=\frac{k_{v} k_{y}}{s^{2}} \prod_{i=1}^{N} G_{r, i}(s)
$$

where $k_{y}$ is the position measurement gain, $k_{v}=\frac{k_{t}}{m}$, with $k_{t}$ is the current-force conversion coefficient and $m$ is the mass of the VCM actuator. $N$ is the number of resonance modes and $G_{r, i}(s)$ for $i=1, \ldots, N$ are their transfer functions.

The system is modeled based on the frequency response identification proposed in [25][26]. Therefore, the following tenth-order model is considered.

$$
G(s)=\frac{6.4013 \times 10^{7}}{s^{2}} \prod_{i=1}^{4} G_{r, i}(s)
$$

with

$$
\begin{gathered}
G_{r, 1}(s)=\frac{0.912 s^{2}+457.4 s+1.433 \times 10^{8}}{s^{2}+359.2 s+1.433 \times 10^{8}} \\
G_{r, 2}(s)=\frac{0.7586 s^{2}+962.2 s+2.491 \times 10^{8}}{s^{2}+789.1 s+2.491 \times 10^{8}} \\
G_{r, 3}(s)=\frac{9.917 \times 10^{8}}{s^{2}+1575 s+9.917 \times 10^{8}} \\
G_{r, 4}(s)=\frac{2.731 \times 10^{9}}{s^{2}+2613 s+2.731 \times 10^{9}}
\end{gathered}
$$

Such resonance modes, if not considered, can degrade the system performance as well as the stability of the closed-loop system. When considered, a notch filter is then necessary to mitigate, as much as possible, their effects and suppress the undesired behavior. The considered notch filter was that proposed in [24].

In this paper, the proposed controller is designed based on the linear model cast with the high frequency response, then a notch filter is inserted to evaluate the performance of the global closed-loop system for a track-following problem under various conditions.

Unexpected external disturbances do affect the HDD and thereafter degrade the tracking performances. Such disturbances are known as input and output disturbances. The input disturbances $w_{\text {in }}$ is generally a color noise caused by the flexure of an electronic bias sensitive to the different mechanical perturbations such as vibrations, resonances and friction [24]. The output disturbances $w_{\text {out }}$ can be caused by the spindle rotation and its effects such as runout media noise, and windage. In our study, we take these perturbations into consideration to show the effectiveness of the proposed controllers against external disturbances as well as uncertainties on the system parameters.

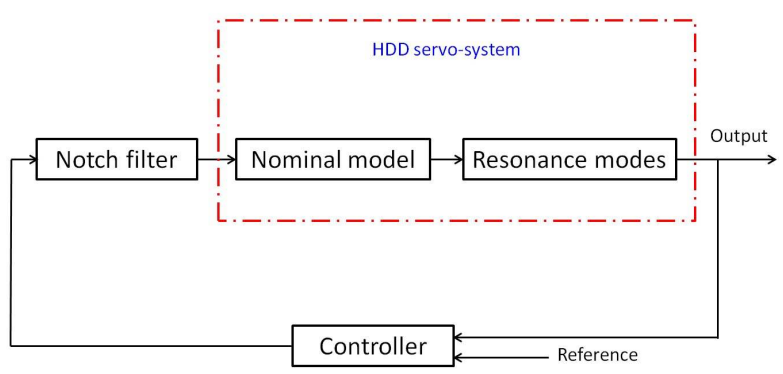

Fig. 2: Block diagram of HDD servo-system

\section{PROPOSED CONTROL SOLUTIONS}

In this section, we propose some control solutions for the track-following problem of the R/W head. Fig. 2 shows the general configuration of the controlled HDD servo-system. The controller is designed based on the nominal model considering the resonance modes. Consequently, to guarantee a good performance of the closed-loop system, a notch filter is then introduced. We present in this section two model predictive based control solutions: classical linear MPC without constraints and linear MPC with multiple coincidence points. The choice of these approaches is motivated by their ability to generate a robust control law and to achieve a good trackfollowing task.

\section{A. Solution 1: Linear Model Predictive Control (MPC):}

During the last decades, MPC showed a great success in many application fields because of its simplicity and effectiveness. The philosophy can be summarized as follow: "Use the process model to predict the behavior of the system and choose the best control sequence resulting from an optimization problem that minimizes a considered cost function subject to some constraints". At each sample time $t=k T_{e}, T_{e}$ is the sampling period, and over a prediction horizon $h_{p}$, a finite horizon control problem is solved, and this by considering the current state of the system as initial condition. The optimization is performed by taking into consideration the dynamics of the system, an objective function, and in some problems, a number of constraints to meet. At each iteration, an optimal control sequence is computed, and only its first sample is applied to the system. All these steps are repeated at each sample time where the horizon is shifted one sample ahead and initial conditions for the optimization become the current measurements. Assume that the system to be controlled is described by the following discrete-time linear state space model:

$$
\begin{aligned}
x_{m}(k+1) & =A_{m} x_{m}(k)+B_{m} u(k) \\
y(k) & =C_{m} x_{m}(k)
\end{aligned}
$$

where $u(k)$ and $y(k)$ are respectively control input and output vectors of the system at instant $k . x_{m}(k)$ is the state vector at instant $k$ assumed to be with dimension $n_{1} . A_{m}, B_{m}$ and $C_{m}$ are the matrices of the system assumed to be known. Inspired from [27], the increments of the state variable and the control 
variable are considered in the process of optimization.

$$
\begin{aligned}
\Delta x_{m}(k+1) & =x_{m}(k+1)-x_{m}(k) \\
\Delta u(k) & =u(k)-u(k-1)
\end{aligned}
$$

Introducing the following new state variable:

$$
x(k)=\left[\begin{array}{ll}
\Delta x_{m}(k)^{T} & y(k)
\end{array}\right]^{T}
$$

a new state space representation is then obtained and considered in the design of the predictive controller using $\Delta u(k)$ as input of the model.

$$
\begin{aligned}
\overbrace{\left[\begin{array}{c}
\Delta x_{m}(k+1) \\
y(k+1)
\end{array}\right]}^{x(k+1)}=\overbrace{\left[\begin{array}{cc}
A_{m} & o_{n_{1}}^{T} \\
C_{m} A_{m} & 1
\end{array}\right]}^{A} \overbrace{\left[\begin{array}{c}
\Delta x_{m}(k) \\
y(k)
\end{array}\right]}^{x(k)}+\overbrace{\left[\begin{array}{c}
B_{m} \\
C_{m} B_{m}
\end{array}\right]}^{B} \Delta u(k) \\
y(k)=\overbrace{\left[\begin{array}{ll}
o_{n_{1}} & 1
\end{array}\right]\left[\begin{array}{c}
\Delta x_{m}(k) \\
y(k)
\end{array}\right]}^{B}
\end{aligned}
$$

where $o_{n_{1}}=\overbrace{\left|\begin{array}{llll}0 & 0 & \ldots & 0\end{array}\right|}^{n 1}$. The triplet $(\mathrm{A}, \mathrm{B}, \mathrm{C})$ is called the extended model and it will be used later. In the next step, and for a well defined set-point trajectory $r(k)$ at each sample time $k$, an objective function is considered to find the optimal control sequence $\Delta U(k)$ of size $h_{c}$, over the control horizon.

$$
\Delta U(k)=\left[\begin{array}{llll}
\Delta u(k) & \Delta u(k+1) & \ldots & \Delta u\left(k+h_{c}-1\right)
\end{array}\right]^{T}
$$

The solution is minimizing a tracking error function between the set-point and the predicted output. The considered cost function $J$ is a quadratic function settled as follows

$$
J=\left(R_{s}-Y\right)^{T}\left(R_{s}-Y\right)+\Delta U^{T} \bar{R} \Delta U
$$

where

- $\left(R_{s}-Y\right)^{T}\left(R_{s}-Y\right)$ is the error function between predicted outputs $Y$ and the vector containing the set-point information over the prediction horizon $h_{p}$ :

$$
\begin{aligned}
R_{s}^{T} & =\overbrace{\left[\begin{array}{lll}
1 & \ldots & 1
\end{array}\right]}^{h_{p}} r(k) \\
Y & \left.=\begin{array}{llll}
y(k) & y(k+1) & \ldots & y\left(k+h_{p}\right.
\end{array}\right]^{T}
\end{aligned}
$$

- $\Delta U^{T} \bar{R} \Delta U$ contains the control input sequence to be determined such as $J$ is made as small as possible.

- $\bar{R}$ is a symmetric positive definite matrix used as a tuning parameter to adjust the performances of the closed-loop system.

The optimal control sequence is computed by deriving $J$ with respect to $\Delta U$. The solution is expressed as [27]

$$
\Delta U=\left(\phi^{T} \phi+\bar{R}\right)^{-1} \phi^{T}\left(R_{s}-F x(k)\right)
$$

where

$$
\begin{aligned}
& F=\left[\begin{array}{llll}
C A & C A^{2} & \ldots & C A^{h_{p}}
\end{array}\right]^{T} \\
& \phi=\left[\begin{array}{cccc}
C B & 0 & \ldots & 0 \\
C A B & C B & \ldots & 0 \\
\vdots & & \ddots & \vdots \\
C A^{h_{p}-1} B & C A^{h_{p}-2} B & \ldots & C A^{h_{p}-h_{c}} B
\end{array}\right]
\end{aligned}
$$

For further details, authors can referred to [27].

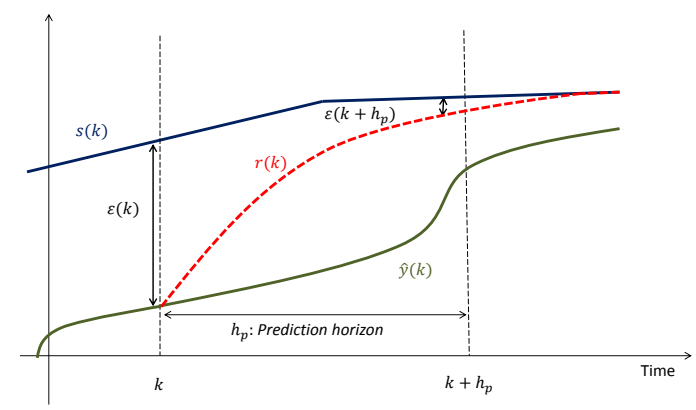

Fig. 3: The basic idea of MPC-CP approach

\section{B. Solution 2: Linear MPC with multiple coincidence points}

Linear MPC with multiple coincidence points (MCP-CP) is a predictive control algorithm which, due to its speed and simplicity, has found its way into different industrial applications [28]. The principal is that the prediction horizon is minimized to a small subset of points, called coincidence points. Consequently, the calculation is simplified and the desired and predicted future outputs are only required to coincide at the considered points in the prediction horizon instead of the entire prediction horizon as in the classical MPC approach. Fig. 3 shows the basic idea of the MPC-CP technique. A set-point trajectory is defined by the trajectory that the output should follow. Here, we denote $s(k)$ the value of the set-point trajectory at time $k$. This approach introduces, besides the set-point trajectory, a reference trajectory which defines the way that the system should return to the set-point as fast as possible. In general, and as we considered in this paper, the reference trajectory takes an exponential form with the time constant $T_{r e f}$ of the exponential, which defines the response speed. At instant $k$, consider the current error to be:

$$
\varepsilon(k)=s(k)-y(k)
$$

where $y(k)$ is the current output of the plant. The reference is chosen such that the error, $i$ steps ahead, and if the output followed it exactly, would be

$$
\begin{aligned}
\varepsilon(k+i)= & \exp ^{-i T_{s} / T_{r e f}} \varepsilon(k) \\
& =\lambda^{i} \varepsilon(k)
\end{aligned}
$$

where $T_{s}$ is the sampling interval. $0<\lambda<1$. The reference trajectory is then defined at instant $k+i$ to be

$$
\begin{aligned}
r(k+i \mid k) & =s(k+i)-\varepsilon(k+i) \\
& =s(k+i)-\exp ^{-i T_{s} / T_{\text {ref }}} \varepsilon(k)
\end{aligned}
$$

The notation $r(k+i \mid k)$ implies that the reference depends on the conditions at time $k$. The goal, as previously stated, is to steer the output of the system to the reference trajectory as soon as possible. For this, coincidence points principle aiming to achieve $r\left(k+P_{i} \mid k\right)=\hat{y}\left(k+P_{i} \mid k\right), i=1 \ldots c$, where $c$ is the number of coincidence points. Often, a least square 
solution is found and this from the minimization of the following criteria:

$$
\sum_{i \in P}[r(k+i \mid k)-\hat{y}(k+i \mid k)]^{2}
$$

where $P$ is the set of subscribes $i$ which corresponds to coincidence points.

Assuming that the input is allowed to change over $h_{c}$ steps ahead, so that the control sequence to calculate is $\hat{u}(k \mid k), \hat{u}(k+1 \mid k), \ldots, \hat{u}\left(h+h_{c}-1 \mid k\right)$. Since $\hat{u}(k \mid k)=$ $\Delta \hat{u}(k \mid k)+u(k-1)$, the predicted outputs can be written as:

$$
\begin{aligned}
\hat{y}\left(k+P_{i} \mid k=\right. & \hat{y}_{f}\left(k+P_{i} \mid k\right)+S\left(P_{i}\right) \Delta \hat{u}(k \mid k)+\ldots \\
& +S\left(P_{i}-h_{c}+1\right) \Delta \hat{u}\left(k+h_{c}-1 \mid k\right)
\end{aligned}
$$

$S\left(P_{i}-j\right)\left(j=0 \ldots h_{c}-1\right)$ is the response of the model to a unit step input $P_{i}-j$ steps ahead. Using a matrix form, equation (20) can be reformulated as:

$$
Y=Y_{f}+\Theta \Delta U
$$

where $\Theta$ is the matrix of the step response given as

$$
\begin{gathered}
\Theta=\left[\begin{array}{ccccccccc}
S\left(P_{1}\right) & S\left(P_{1}-1\right) & \ldots & 0 & \ldots & 0 & 0 & \ldots & 0 \\
S\left(P_{2}\right) & S\left(P_{2}-1\right) & \ldots & \ldots & \ldots & \ldots & 0 & \ldots & 0 \\
\vdots & \vdots & \vdots & \vdots & \vdots & \vdots & \vdots & \vdots & \vdots \\
S\left(P_{c}\right) & S\left(P_{c}-1\right) & \ldots & \ldots & \ldots & \ldots & \ldots & \ldots & S\left(P_{c}-h_{c}+1\right)
\end{array}\right] \\
\Delta U=\left[\begin{array}{llll}
\Delta \hat{u}(k \mid k) & \Delta \hat{u}(k+1 \mid k) & \ldots & \Delta \hat{u}\left(k+h_{c}-1 \mid k\right)
\end{array}\right]^{T}
\end{gathered}
$$

and $Y_{f}$ is the free response of the plant

$$
Y_{f}=\left[\begin{array}{llll}
\hat{y}_{f}\left(k+P_{1} \mid k\right) & \hat{y}_{f}\left(k+P_{2} \mid k\right) & \ldots & \hat{y}_{f}\left(k+P_{c} \mid k\right)
\end{array}\right]^{T}
$$

The least-squares optimal solution is that expressed as

$$
\Delta U=\Theta^{+} \Gamma-Y_{f}
$$

where $\Gamma$ is the matrix of the corresponding values of the reference trajectory at the different coincidence points expressed as

$$
\Gamma=\left[\begin{array}{llll}
r\left(k+P_{1} \mid k\right) & r\left(k+P_{2} \mid k\right) & \cdots & r\left(k+P_{c} \mid k\right)
\end{array}\right]^{T}
$$

$\Theta^{+}$is the pseudo-inverse of $\Theta$. Applying the first sample of the optimal computed sequence $\Delta U$, the control input of the plant is then:

$$
u(k)=\Delta \hat{u}(k \mid k)+u(k-1)
$$

Further details of the approach are presented in [28].

\section{Simulations RESUlts: A COMPARISON STUDY}

In this section, simulation results of the different proposed control approaches are presented and discussed. The overall model of the system, as described by equations (2)-(6), is used to determine the system characteristics, such as output displacement of the $\mathrm{R} / \mathrm{W}$ head, the evolution of the control input, the cost function evolution in case of predictive scheme (classical MPC and MPC-CP), under various simulation conditions. The first scenario deals with a track-following problem in case of variable set-point trajectory varying from 0 to $1 \mu \mathrm{m}$ and this with the consideration of a measurement noise affecting the actuator. The later is assumed to be a zeromean Gaussian white noise with a variance $\sigma^{2}=10^{-4}(\mu \mathrm{m})^{2}$. However, in the second scenario, and for reasons of clarity of the simulation results, a constant reference of $1 \mu \mathrm{m}$ is considered and external disturbances are introduced in two different moments to show the rejection scenario for both input and output disturbances. The output perturbation $w_{\text {out }}$ is assumed to be an impulse with an amplitude of $0.3 \mu \mathrm{m}$ applied to the system at time $t=3.5 \mathrm{~ms}$. The input disturbance $w_{\text {in }}$ is an unknown perturbation satisfying $\left|w_{i n}\right| \leq 3 m V$. In this study, and for reasons of simplicity, we suppose that $w_{i n}=-3 m V$ [24], and it is applied to the systeme at time $t=6 \mathrm{~ms}$. Finally, the last scenario is carried out with modeling uncertainties on the system's parameters. Uncertainties of $40 \%$ and up to $80 \%$ on different parameters are introduced and simulations are compared with those with nominal values. The considered parameters are $m=0.01595 K g, k_{t}=1.0210 \times 10^{6}$ and $k_{y}=1$. Initial conditions of state variables and control input are chosen at the origin. The sampling frequency is fixed at $20 \mathrm{KHz}$. Table I presents the considered synthesis parameters for the proposed controllers, while Table II is a summary of the different controllers' performances. For the purpose of comparison, an energy function $E$ is considered. It is expressed as follows:

$$
E=\sum_{i}\left|u_{i}\right|, \quad i=1 \ldots N_{\text {sim }}
$$

where $N_{\text {sim }}$ is the number of samples for duration of simulation.

\section{A. Scenario 1: Tracking problem under nominal conditions}

Figure 4 and figure 5 show the different simulation results. All the proposed control approaches are able to control the output to follow its desired reference trajectory. However, it is clear that MPC-CP controller is the fastest one with the smallest overshoot. The ability of an MPC scheme to predict the behavior of the system is perceptible through Fig.4 (b) and (c) where the controller anticipate the transition of the set-point trajectory from 0 to $1 \mu \mathrm{m}$ which is not the case with a classical PID as shown in figure 4 (a).

\section{B. Scenario 2: Tracking following with punctual distur- bances}

In this scenario, the idea is to test the effect of an external impulse disturbances on the VCM actuator behavior and how the proposed controllers deal with. The results are shown in figure 6 and figure 7 . It can be clearly seen that, for all the controllers, the two considered disturbance are rejected. With an MPC controller we have better results than with a PID. Indeed, less energy is consumed and smaller time is made to return to the desired trajectory. However, compared with

\begin{tabular}{|c|c|c|c|c|c|c|c|c|}
\hline \multicolumn{2}{|c|}{ PID } & \multicolumn{3}{c|}{ MPC } & \multicolumn{3}{c|}{ MPC-CP } \\
\hline \hline$K_{p}$ & $K_{i}$ & $K_{d}$ & $h_{p}$ & $h_{c}$ & $\bar{R}$ & $h_{p}$ & $h_{c}$ & $T_{r e f}$ \\
\hline $4.5 \times 10^{-3}$ & $2 \times 10^{-4}$ & 0.85 & 30 & 3 & $100 I$ & 5 & 2 & $5 \times 10^{-4}$ \\
\hline
\end{tabular}

TABLE I: Summary of comparison study 
(a)

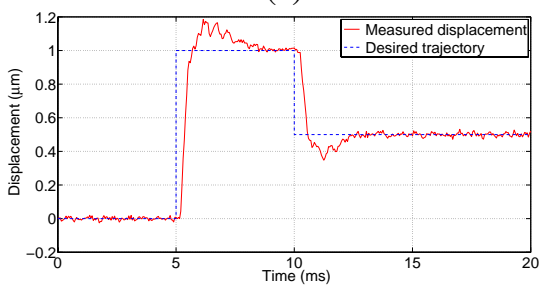

(b)

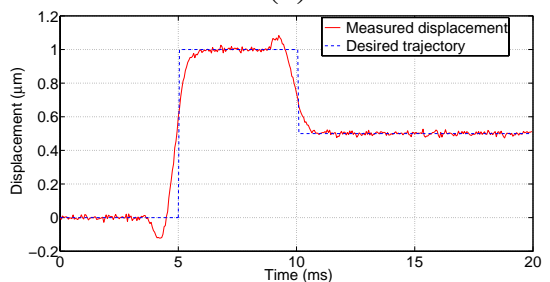

(c)

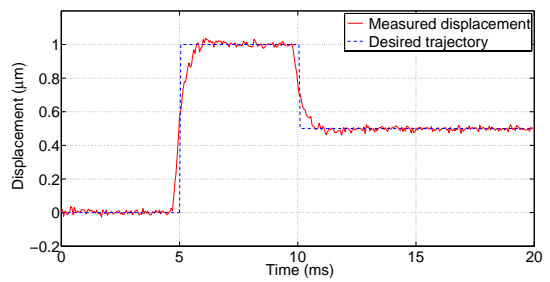

Fig. 4: Tracking problem in nominal conditions: Evolution of the output displacement: (a) with PID,(b) with LMPC, and (c) with LMPC-CP

(a)

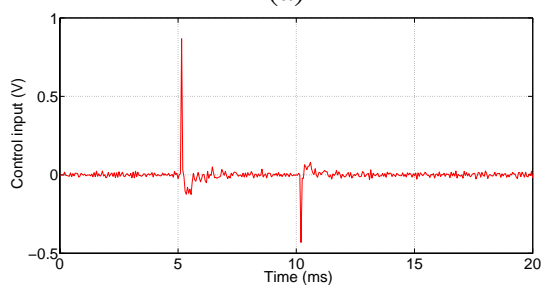

(b)

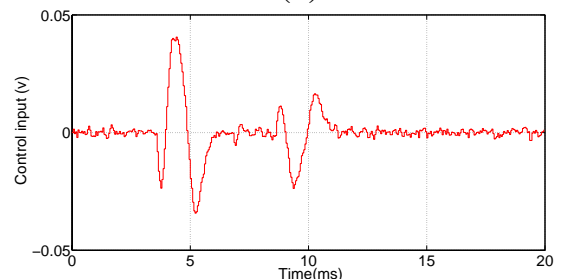

(c)

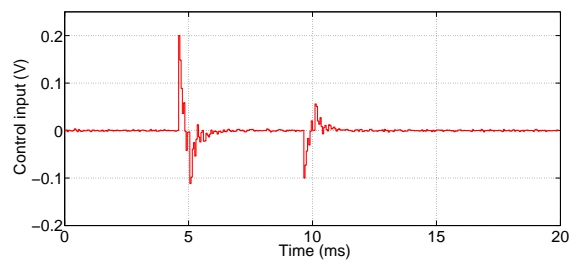

Fig. 5: Tracking problem in nominal conditions: Evolution of the control input: (a) with PID,(b) with LMPC, and (c) with LMPC-CP

(a)

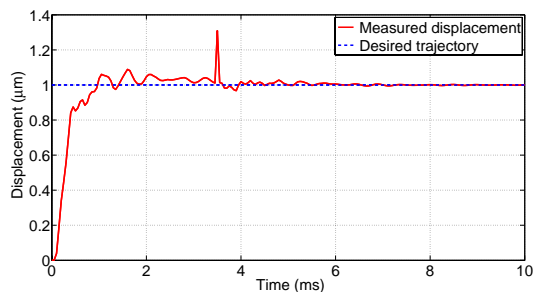

(b)

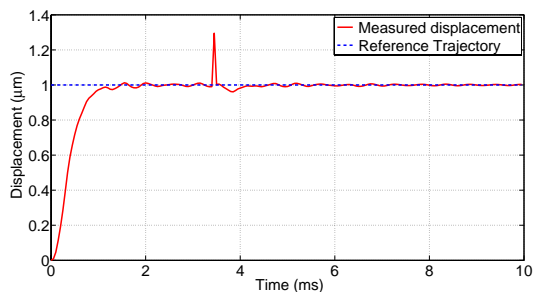

(c)

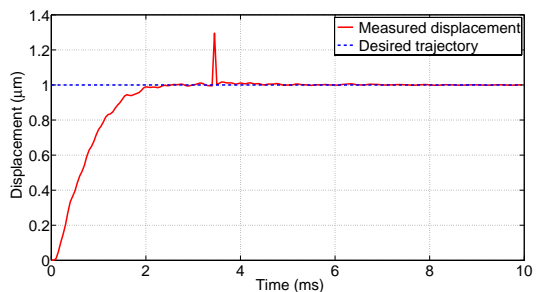

Fig. 6: Tracking following with punctual disturbance: Evolution of the output displacement: (a) with PID,(b) with LMPC, and (c) with LMPC-CP

(a)

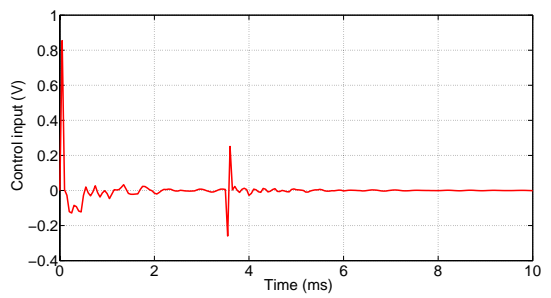

(b)

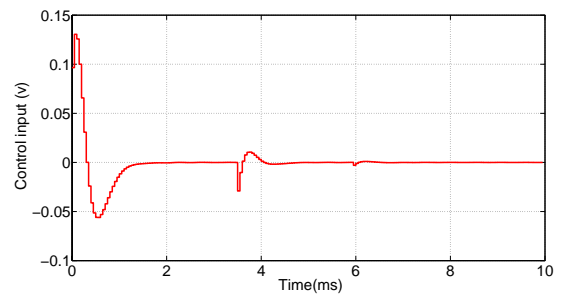

(c)

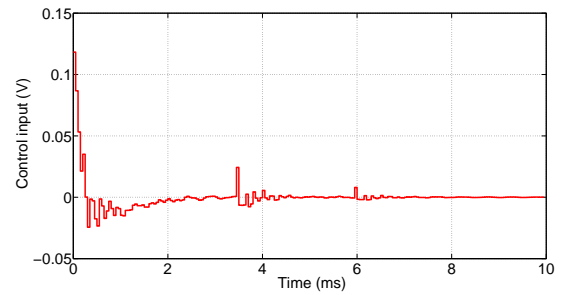

Fig. 7: Tracking following with punctual disturbance: Evolution of the control input: (a) with PID,(b) with LMPC, and (c) with LMPC-CP

results obtained with an MPC-CP, it is clear that the rejection of the disturbances is faster with this latter.

\section{Scenario 3: Robustness as a function of parameters' uncertainties}

In this scenario, and in order to evaluate each controller's robustness against uncertainties, we have considered uncertainties on three parameters of the system: the mass, the position measurement gain, and the current-force conversion coefficient of the VCM actuator. The obtained results for this simulation case study are presented in Fig. 8 and Fig. 9. For an uncertainty amount up to $80 \%$ with respect to nominal value, the response performances with a PID controller are so degraded with high overshoot and much oscillations to reach the desired path as shown in figure 8 (a) and figure 9 (a). However, with a classical MPC, we have better results in terms of speed, but the overshoot remains relatively important as shown in Fig.8 (b) and Fig.9 (b). Simulation results with the MPC-CP controller are depicted in figure 8 (c) and figure 9 (c). This approach shows excellent robustness and minimal effects with up to $80 \%$ parameter uncertainty.

\section{CONCLUSION AND FUTURE WORKS}

In this work, two approaches of linear MPC control, classical and with multiple coincidence points (MPC-CP), are proposed to deal with a track-following problem of a $\mathrm{R} / \mathrm{W}$ head of a HDD where have never been previously applied on such servo-system. The MPC-CP controller has 
(a)

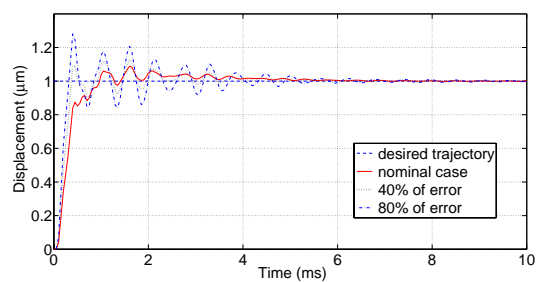

(b)

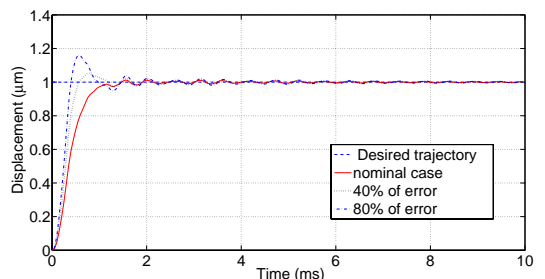

(c)

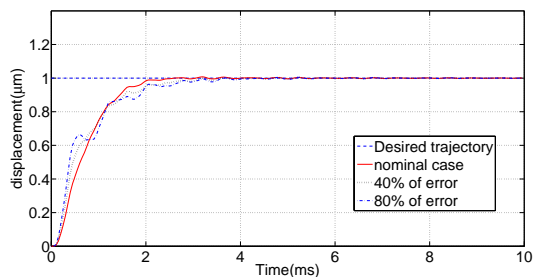

Fig. 8: Robustness towards parameters' uncertainties: Evolution of the output displacement: (a) with PID,(b) with LMPC, and (c) with LMPC-CP

(a)

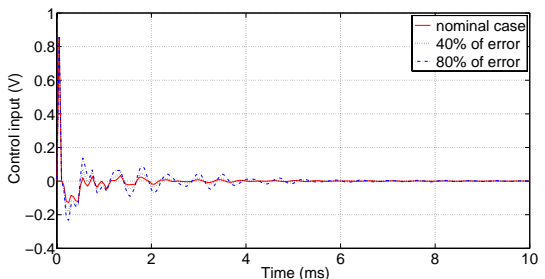

(b)

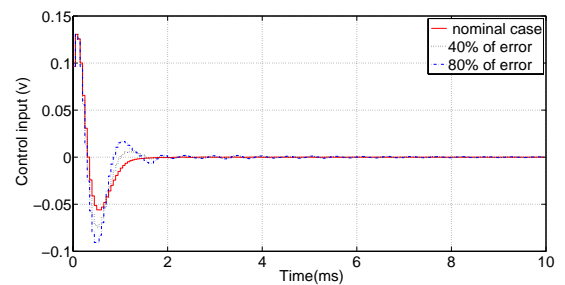

(c)

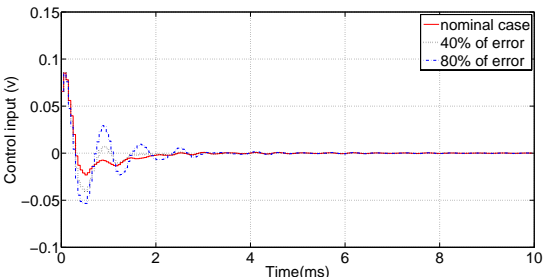

Fig. 9: Robustness towards parameters' uncertainties: Evolution of the control input: (a) with PID,(b) with LMPC, and (c) with LMPC-CP

\begin{tabular}{cccc}
\hline Nominal conditions & PID controller & MPC controller & MPC-CP controller \\
\hline Settling time & $2.73 \mathrm{~ms}$ & $1.7 \mathrm{~ms}$ & $1.07 \mathrm{~ms}$ \\
Maximum overshoot & $19 \%$ & $13 \%$ & $4 \%$ \\
Energy function (E) & $6.5 \mathrm{v}$ & $1.79 \mathrm{v}$ & $1.94 \mathrm{v}$ \\
\hline Punctual disturbance & & & $1.2 \mathrm{~ms}$ \\
Recovery time & $2.05 \mathrm{~ms}$ & $1.05 \mathrm{~ms}$ & $30 \%$ \\
Maximum overshoot & $31.3 \%$ & $30 \%$ & $0.75 \mathrm{v}$ \\
Energy function (E) & $3.12 \mathrm{v}$ & $2.21 \mathrm{v}$ & $2.3 \mathrm{~ms}$ \\
\hline Parameters uncertainties (80\% of error) & & & $0.52 \%$ \\
\hline Settling time & $3.36 \mathrm{~ms}$ & $1.35 \mathrm{~ms}$ & $1.05 \mathrm{v}$ \\
Maximum overshoot & $28.13 \%$ & $16.2 \%$ & $1.37 \mathrm{v}$ \\
\hline Energy function (E) & $5.07 \mathrm{v}$ & & \\
\hline
\end{tabular}

TABLE II: Controllers performance comparison

a much better performance compared to those of the linear MPC and classical PID controller. This method was observed to achieve faster tracking and lower overshoot than the PID and MPC controllers. Moreover, superior disturbance rejection and robustness against parameters' uncertainties were observed with an MPC-CP technique than the two other controllers. Further, research will be focused on predictive algorithms to address the trajectory tracking of nonlinear dynamics of a micro HDD.

\section{REFERENCES}

[1] Y. Huang, W.C. Messner, and J. Steele, Feed-forward algorithms for time-optimal settling of hard disk drive servo systems, Proc 23rd Int. Conf. Ind. Electron. Contr. Instrum., New Orleans, LA, pp. 527, 1997.
[2] H. Fujimoto, Y. Hori, T. Yarnaguchi, and S. Nakagawa, Proposal of seeking control of hard disk drives based on perfect tracking control using multirate feedforward control, Proc. 6th Int. Workshop Adv. Motion Control, Nagoya, pp. 749, Japan, 2000.

[3] B. M. Isayed and M. A. Hawwa, A nonlinear PID control scheme for hard disk drive servosystems, Proc. 15th Med. Conf. on Control and Automation, pp. 1-6, 2007.

[4] R. Horowitz and B. Li, A daptive control for disk file actuators, Proc. 34th Conf. on decision and control, New Orleans, LA, 1995.

[5] M. Kobayashi, S. Nakagawa, and H. Numasato, Adaptive control of dual-stage-actuator for hard disk drives, Proc. American Control Conference, Boston, 2004.

[6] T. Yamaguchi, K. Shishida, S. Tohyama, Y. Soyama, H. Hosokawa, H. Ohsawa, H. Numasato, T. Arai, K. Tsuneta, and H. Hirai, A modeswitching controller with initial value compensation for hard disk drive servo control, Control Eng. Practice, vol. 5, no.11, pp. 1525-1532, 1997.

[7] T. Yamaguchi and H. Hirai, Control of transient response on a servosystem using mode-switching control, and its application to 
magnetic disk drives, Control Eng. Practice, vol. 6, pp. 1117-1123, 1998.

[8] V. Venkataramanan, Ben M. Chen, Tong H. Lee, and G. Guo, A new approach to the design of mode switching control in hard disk drive servo systems, Control Eng. Practice, vol. 10, pp. 925939, 2002.

[9] J. Nie, E. Sheh, and R. Horowitz, Optimal $H_{\infty}$ control for hard disk drives with an irregular sampling rate, American Control Conference, San Francisco, CA, USA, 2011.

[10] M.R. Graham and R.A de Callafon, Modeling and robust control for hard disk drives, ASME/JSME, Conf. on Micro. for inf. and Prec. Equi. (MIPE), Santa Carla, CA, 2006.

[11] M. Hirata, M. Takiguchi, and K. Nonami, Track-following control of hard disk drives using multi-rate sampled-data $H_{\infty}$ control, Proc. 42nd Conf. on decision and control, Maui, Hawaii, USA, 2003.

[12] B. Teck Goh, Li Zhongming, M. Ben Chen, L. Tong Heng, and T. Huang, Design and implementation of a hard disk drive servo system using robust and perfect tracking approach, IEEE Trans. on control systems technology, vol. 9, no. 2, 2001.

[13] G. Cheng, K. Peng, M. Chen Ben, and H. Tong Lee, A microdrive track-following controller design using robust and perfect tracking control with nonlinear compensation, Mechatronics 15, pp. 933948, 2005.

[14] E.F. Camacho, and C.Bordons, Model predictive Control, Ed. springerverlag, London, 2004

[15] D.W. Clarke, Application to generalized predictive control to industrial processes, IEEE Control Systems Magazine, vol. 22, pp. 49-55, 1988.

[16] M. Susanu, D. Dumur, M. Aubourg, and C. Wartelle, Virtual machinetool environement Design and validation, $6^{\text {th }}$ International Conference on High Speed Machining, San Sebastian, 2007.

[17] C.R. Cutler,and B.C. Ramaker, Dynamic matrix control-A computer control algorithm, Automatic Control Conference, San Francisco, 1980.

[18] C.E. Garca, D.M. Prett,and M. Morari, Model predictive control : Theory and practice a survey, Automatica, vol. 25(3), pp. 335-348, 1989.

[19] J.W. Eaton, and J.B. Rawlings, Model predictive control of chemical processes, Chemical Engineering Science, vol. 47(4), pp. 705-720, 1992.

[20] J.R. Cueli, and C. Bordons, Iterative nonlinear model predictive control. Stability, robustness and applications, Control Engeneering Practice, vol. 16(9), pp. 1023-1034, 2008.

[21] R. Bhattacharya, G.J. Balas, M.A. Kaya,and A. Packard, Nonlinear receding horizon control of an F-16 aircraft, Journal Guidance Control and Dynamics, vol. 25(5), pp. 924-931, 2002.

[22] J.E. Normey-Rico, and E.F. Camacho, Control of dead-time processes, Springer-Verlag London, 2007.

[23] S.J. Qin, and T. Badgwell, An Overview of Industrial Model Predictive Control Technology, Chemical Process ControlTahoe, California, 1996.

[24] B. M. chen, T. H. Lee, K. Peng, and V. Venkataramanan, Hard Disc Drive servo sytems, 2nd edition, Advances in Industrial Control, springer, 2006.

[25] P. Eykhoff, System Identification Parameter and State Estimation, New York, Wiley, 1981.

[26] L. Wang, L.Yuan, B.M. Chen, and T.H. Lee, Modeling and control of a dual actuator servo system for hard disk drives, Technol., Hsinchu, Taiwan. R.O.C.,pp.533-538, 1998

[27] L. Wang,Model predictive control system design and implementation using Matlab, Advances in Industrial Control, springer, 2009.

[28] J.M. Maciejowski, Predictive Control with Constraints, Pearson Education Limited, Harlow, Essex., 2002.

[29] C. W. Lee and S. M. Suh, Model prediction based dual-stage actuator control in discrete-time domain, IEEE Trans. on magnetics, vol. 47, no. 7, 2011 .

[30] J.H. Lee and B.L. Cooley, Robust model predictive control of multivariable systems using input-output models with stochastic parameters, Proceedings of the American Control Conference, vol. 5, pp. 36943698, 1995.

[31] D. Nagrath, V. Prasad, B.W. Bequette and H.P. Isermann, Model predictive control of open-loop unstable cascade systems, Proceedings of the American Control Conference, vol. 6, pp. 3747-3752, 2000.

[32] G. Karer, G. Music, I. Skrjanc and B. Zupancic, Model predictive control of nonlinear hybrid systems with discrete inputs employing a hybrid fuzzy model, Nonlinear analysis. Hybrid systems, vol. 2, no. 2 pp. 491-509, 2008.
[33] N. Poursafar, H.D. Taghirad and M. Haeri, Model predictive control of non-linear discrete time systems: a linear matrix inequality approach, IET Control Theory and Appl., vol. 4, pp. 1922-1932, 2010. 